\title{
Hypertension and Obesity: A Cross-Sectional Study
}

\author{
Jehanzeb Akram, Hafiz Raza Rehman, Fahad Muneer, Sarmad Hassan, Rida Fatima, \\ Tayyab Mumtaz Khan, Mahak Khizar, Sara Tahir, Mahpara Asim, Mubashra Shabbir, \\ Shanza Asif, and Madeeha Mumtaz
}

\section{ABSTRACT}

Hypertension is a common health issue all over the world. It has been suggested that hypertension leads to diseases of vital organs like, heart, brain, and kidney. Although, hypertension is under the influence of many factors like age, gender, marital status, genetic, social class, educational status, diabetes, lifestyle, and tobacco and alcohol consumption, even so, obesity is considered as a very critical factor. Thus, our study was established with the objective to determine interrelation between hypertension and obesity. This study with cross-sectional design was accomplished among general and regional population of Pak Arab society, Lahore in about 2months from March 2021 to the end of April 2021. People were called up in our study via established criteria. Data was collected by self-designed proforma and WHO classification was applied to classify participants into four WHO classes of weight status. Data analysis was done by applying SPSS version 25. Diverse statistical tests like Chi-square test, independent sample t-test, and One-Way-ANOVA test. were used to evaluate study variables. This study shows overall high prevalence of both hypertension $(45.1 \%)$ and obesity $(30.70 \%)$ among study population. Mean values of both blood pressures systolic and diastolic were higher among men (systolic blood pressure $=\mathbf{1 4 2 . 3 4} \mathbf{m m H g}$ with SD of $\pm \mathbf{1 8 . 0 3}$, diastolic blood pressure $=89.93 \mathrm{mmHg}$ with SD of \pm 1.26 ), than women (systolic blood pressure $=136.64 \mathrm{mmHg}$ with SD of \pm 19.95 , diastolic blood pressure $=$ $89.65 \mathrm{mmHg}$ with SD of \pm 8.67 ) however, these differences were not significant statistically with p-values 0.75 and 0.851 respectively. BMI mean values were higher among women (25.95 with SD of \pm 3.67$)$ than men (25.76 with SD of \pm 4.10$)$ ), and difference was insignificant statistically ( $p=0.779$ ). Variation in mean BMI values across four weight statuses (For Underweight BMI mean value $=17.86$ with $\mathrm{SD}$ of \pm 0.38 , for normal weight $\mathrm{BMI}$ mean value $=21.18$ with SD of \pm 1.36 , for overweight $B M I$ mean value $=25.48$ with SD of \pm 1.10 , for obese BMI mean value $=30.47$ with SD of \pm 0.77 ) was significant $(p=0.0003)$. Difference in $B M I$ mean values was also significant between hypertensive $(\mathrm{BMI}=\mathbf{2 7 . 6 8}$ with $\mathrm{SD}$ of \pm 3.28$)$ and normotensive people $(B M I=24.39$ with $S D$ of \pm 3.62$)$ with p-value of 0.0001 . Variations in mean values of both systolic (underweight $=127.57 \mathrm{mmHg}$ with $\mathrm{SD}$ of \pm 10.67 , normal weight $=126.89 \mathrm{mmHg}$ with $\mathrm{SD}$ of \pm 9.63 , over weight $=135.52 \mathrm{mmHg}$ with SD of \pm 17.46 , obese $=152.6 \mathrm{mmHg}$ with $\mathrm{SD}$ of \pm 19.74 ) and diastolic blood (underweight $=81.71 \mathrm{mmHg}$ with $\mathrm{SD}$ of \pm 7.29 , normal weight $=83.21 \mathrm{mmHg}$ with SD of \pm 4.68 , over weight $=89.39 \mathrm{mmHg}$ with $\mathrm{SD}$ of \pm 7.57 , obese = $95.40 \mathrm{mmHg}$ with SD of \pm 9.75$)$ pressures across four statuses were significant with $p$ values 0.004 and 0.0001 respectively. Gender was associated with weight status significantly $(p=0.040)$; however, gender was not associated with hypertension $(p=0.072)$ Most importantly, obesity and hypertension were associated significantly $(p=0.0003)$ In summary, our study shows high prevalence of hypertension and obesity among enrolled population. Hypertension incidence goes up with increase in the weight. Hypertension incidence was higher among men than women whereas, obesity was higher among women than men. Thus, we can by controlling obesity we would be able to manage hypertension.

Keywords: Hypertension, Obesity, Cross-sectional, Study, Association.
Submitted : June 10, 2021

Published : July 28, 2021

ISSN: $2593-8339$

DOI: 10.24018 /ejmed.2021.3.4.928

Jehanzeb Akram

Rahbar Medical and Dental College,

Pakistan.

Hafiz Raza Rehman

Rahbar Medical and Dental College, Pakistan.

Fahad Muneer

Rahbar Medical and Dental College, Pakistan.

Sarmad Hassan

Rawalpindi Medical University, Rawalpindi, Pakistan.

Rida Muneer

Rahbar Medical and Dental College, Pakistan.

Tayyab Mumtaz Khan*

Rawalpindi Medical University, Pakistan.

(e-mail :tayyab.mkhan98@gmail.com) Mahak Khizar

Rahbar Medical and Dental College, Pakistan.

Sara Tahir

Rahbar Medical and Dental College, Pakistan.

Mahpara Asim

Rahbar Medical and Dental College, Pakistan.

Mubashra Shabbir

Islamic International Medical College, Pakistan.

Shanza Asif

Islamic International Medical College, Pakistan.

Madeeha Mumtaz

Lahore College for Women University, Pakistan.

*Corresponding Author

\section{INTRODUCTION}

Hypertension prevalence is increasing day by day all over the world not just in third class countries but also in first class countries [1], [2]. Hypertension leads to 7.5 million deaths around the globe annually. It is estimated number of deaths because of hypertension would be reached to 1.56 billion in 2025 [3], [4]. Along with all other countries of world picture of hypertension is alike in Pakistan. According to one National Health Survey reported that $18 \%$ of adults and 33 adults with age more than 40 are affected by hypertension. It was also indicated that only around $50 \%$ of all hypertensives were diagnosed while only half of those were treated for high 
blood pressure. As a result of ignorance of diagnosis and no proper treatment for all diagnosed, only $12.8 \%$ hypertensive patients of all were managed properly [5]. Even though most of the people with raised blood pressure remain undiagnosed because of asymptomatic nature of hypertension but a proportion of people present with headaches, dizziness, loss of balance and change in vision [6]. Hypertension leads to death through many lethal diseases including Stroke, chronic heart disease, coronary heart disease and renal disorder [3], [7]-[10]. Besides above-mentioned diseases hypertension also causes retinal hemorrhage and peripheral vascular disease [3], [11]. Hypertension is under the influence of many factors like male gender, age, marital status, top social-class, lower educational status, tobacco and alcohol consumption, diabetes, kind of activities, and family history of hypertension [11]-[13]. Along with these reported factors in various studies, obesity has been also recorded in literature, as one of major risk factors for the development of hypertension. Although all these factors important to control hypertension, however, obesity is most important as it is known as root cause of many other cardiovascular diseases like heart failure and coronary heart disease, endocrine disorders, and cancers of various parts of human body. Thus, its control not only just would cause control of hypertension, but it would also bring reduction in other chronic and malignant diseases of body [14]-[17]. Serious measures should be taken to reduce obesity. Despite, many studies throughout the world have been conducted to determine the impact of obesity on hypertension, in literature, researches that provide knowledge about influence of obesity on hypertension in Pakistan, are scanty. Therefore, in the light of limited information about obesity and hypertension at our national and particularly at local level, our study is set with objective to determine association of hypertension and obesity among regional and general people of Pak Arab Society, Lahore, Pakistan. If the result of current study suggests that hypertension is affected by obesity then by application of suitable interventions for obesity or weight reduction, we would be able to control raised blood pressure and consequently, incidence of hypertension related death incidence would also go down.

\section{MATERIALS AND METHODS}

\section{A. Study Design and Study Population}

We applied descriptive cross-sectional study design in our present study. This study was carried out among general population of Lahore, Pakistan in almost 2 months from March 2021 till the end of April 2021. 153 willing participants whose age was above 30 years but not more than 60 were called up in study in pursuance of set exclusion and inclusion criteria. Those people whose age was not according to our set criteria were excluded from study. We applied one self-designed proforma for data collection. Then we gave relevant information regarding the objectives of study. In next step we took informed consent from all participants for participation in present study. Proformas were filled up by interview and relevant examinations of all enrolled participants.
B. Assessment of Demographic Details and Menopausal Status of Study Population

We used a Self-designed proforma to obtain suitable and essential data about the demographic elements like, age and gender. After noting demographics details, we checked blood pressure (BP), first we used Palpatory method and then for confirmation and diastolic BP assessment we used Auscultatory method. Only Sphygmomanometer was used during palpatory method while both Sphygmomanometer and stethoscope were used during auscultatory method. Then it was noted on self-structured proforma. People with Systolic BP more than $140 \mathrm{mmHg}$ and Diastolic BP more than 90 were considered as hypertensive while below these values were considered normotensive.

\section{Assessment of Obesity}

Height in meters and weight in kilograms were measured and were noted on proforma. Then before using WHO classification of Weight Status which is based on BMI (Body Mass Index), we calculated BMI with the help of height and weight of participants. Participants were then classified into four different groups based on BMI. Underweight with BMI= less than18.5, Normal Weight with $\mathrm{BMI}=18.5$ to 24.9, Overweight with BMI $=25$ to 29.9 , and Obese with $\mathrm{BMI}=30$ and more than 30 . To calculate BMI Weight in kilograms was divided by height in meters in squared. To measure height and weight, measuring tape and weighing machine were used respectively. Their measured values were recorded on proforma as well.

\section{Data Analysis}

SPSS version. 25 was put into action for data analysis. Chi square analysis was utilized, to determine the association between gender and obesity, gender, and hypertension, between and between obesity and hypertension. Significance of difference in BMI mean values and blood pressure between females and males was estimated by using independent sample t-test. Then One Way ANOVA test was used to determine the disparity of BMI among the four classes of weight statuses and variation in systolic and diastolic blood pressures mean values across the four weight statuses. The pvalue less than 0.05 was considered statistically significant.

\section{RESULTS}

In our present study out of 153 enrolled people. $94(61.4 \%)$ were females and 59 (38.6\%) were males. For recruited population means of various variables including age, BMI, systolic blood pressure and diastolic blood pressures were 41.66years (with SD of \pm 8.61 ), 25.87 (with SD of \pm 3.83 ), $138.84 \mathrm{mmHg}$ (with SD of \pm 19.37 ), and $89.76 \mathrm{mmHg}$ (with $\mathrm{SD}$ of \pm 9.10$)$ respectively. In our study normotensive people were $84(54.9 \%)$ while hypertensive people were $69(45.1 \%)$. Means of systolic blood pressure $(142.34 \mathrm{mmHg}$ with SD of $\pm 18.03)$ and diastolic blood pressure $(89.93 \mathrm{mmHg}$ with SD of \pm 1.26 ) for male sex were higher than means of systolic blood pressure $(136.64 \mathrm{mmHg}$ with $\mathrm{SD}$ of \pm 19.95$)$ and diastolic blood pressure $(89.65 \mathrm{mmHg}$ with $\mathrm{SD}$ of \pm 8.67$)$ for female sex although these differences in systolic and diastolic blood pressures across the gender were insignificant statistically. Significance of these variation in above 
mentioned both systolic and diastolic blood pressure were checked through independent sample t-test and p-values for assessment of difference in systolic and diastolic blood pressure were 0.75 and 0.851 , respectively. Moreover, hypertension was not associated with gender significantly $(\mathrm{p}=0.072)$ and it was done by chi-square test.

Table I elaborates the percentages of four distinct weight statuses in accordance with BMI of participants first as a whole population then across the gender and in the last between normotensive and hypertensive people. Its shows that $30.7 \%$ were obese which means that prevalence was high among enrolled people. It also reveals that obesity prevalence was higher among female sex as compared to male sex. Likewise, obesity prevalence was also higher among hypertensive people in comparison to normotensive people. Moreover, it also displays that weight status and gender have statistically significant relationship as p-value for chi-square test is 0.040 and similarly, the association of weight status and blood pressure is also quite significant statistically as pvalue is 0.0003 for chi-square test.

Table II displays disparity in mean values of BMI depend on gender and blood pressure status of study population together with results of independent sample t-test and the difference in mean BMI value across the gender was statistically insignificant $(\mathrm{p}=0.779)$ while the difference in BMI mean values was significant statistically $(\mathrm{p}=0.0001)$ between normotensive and hypertensive people.

Table III indicates the difference in mean values of BMI among four weight statuses of study population. The divergence in BMI mean values was significant statistically $(\mathrm{p}=0.0003)$ among all weight statuses and it was determined by One-Way ANOVA test.
Table IV manifests that differences in mean systolic and diastolic blood pressures values among four weight statuses. These variations were significant statistically for both systolic and diastolic blood pressure mean values with p-values 0.004 and 0.0001 respectively assessed by One Way ANOVA test.

Our study reveals overall high Prevalence of hypertension and obesity in study population. Obesity is more prevalent among women in comparison to men while hypertension is more prevalent among men as compared to women. Obesity significantly influences blood pressure, and they have significant association.

TABLE II: VARIATION S IN MEAN BMI VALES IN ACCORDANCE TO GENDER AND BLOOD PRESSURE STATUS ALONG WITH INDEPENDENT SAMPLE TTEST ANALYSIS

\begin{tabular}{|c|c|c|c|}
\hline & \multirow[t]{2}{*}{ Parameter } & \multirow{2}{*}{$\frac{\text { BMI value }}{\text { Mean }( \pm \mathrm{SD})}$} & $\begin{array}{l}\text { Independent } \\
\text { Sample t-test }\end{array}$ \\
\hline & & & p-value \\
\hline \multirow{2}{*}{ Gender } & Women & $25.95( \pm 3.67)$ & \multirow{2}{*}{0.779} \\
\hline & Men & $25.76( \pm 4.10)$ & \\
\hline \multirow{2}{*}{$\begin{array}{c}\text { Blood } \\
\text { Pressure } \\
\text { Status }\end{array}$} & Normotensive & $24.39( \pm 3.62)$ & \multirow[b]{2}{*}{0.0001} \\
\hline & Hypertensive & $27.68( \pm 3.28)$ & \\
\hline
\end{tabular}

TABLE III: VARIATION IN MEAN OF BMI VALUES DEPEND ON WEIGHT STATUSES IN CONJUNCTION WITH ONE-WAY ANOVA ANALYSIS

\begin{tabular}{cccc}
\hline \multirow{2}{*}{ Parameter } & BMI value & $\begin{array}{c}\text { One Way } \\
\text { ANOVA }\end{array}$ \\
\cline { 3 - 4 } & & Mean \pm S. D & p-value \\
\hline \multirow{3}{*}{ Weight } & Underweight & $17.86( \pm 0.38)$ & \\
Status & Oormal Weight & $21.18( \pm 1.36)$ & \multirow{2}{*}{0.0003} \\
& Over Weight & $25.48( \pm 1.10)$ & \\
\hline
\end{tabular}

TABLE I: POPUlation PARAMETERS TOGETHER With THEIR CROSS-TABUlATION With STUDY VARIABlSES AND CHI-SQUARE ANALYSIS

\begin{tabular}{|c|c|c|c|c|c|c|}
\hline \multicolumn{7}{|c|}{ Cross-Tabulation and chi-square analysis } \\
\hline & & \multicolumn{4}{|c|}{ Weight Status } & \multirow{2}{*}{$\begin{array}{c}\text { Chi- } \\
\text { Square } \\
\text { Analysis }\end{array}$} \\
\hline \multicolumn{2}{|c|}{ Parameter } & Underweight & Normal Weight & Over Weight & Obese & \\
\hline \multicolumn{2}{|c|}{ Total $=153$} & $7(4.61 \%)$ & $28(18.32 \%)$ & $71(46.41 \%)$ & $47(30.70 \%)$ & p-value \\
\hline \multirow[b]{2}{*}{ Gender } & $\begin{array}{l}\text { Women } \\
(\mathrm{n}=94)\end{array}$ & $1(1.06 \%)$ & $20(21.27 \%)$ & $42(44.68 \%)$ & $31(32.98 \%)$ & \multirow{2}{*}{0.040} \\
\hline & $\begin{array}{l}\text { Men } \\
(\mathrm{n}=59)\end{array}$ & $6(10.17 \%)$ & $8(13.55 \%)$ & $29(49.15 \%)$ & $16(27.12 \%)$ & \\
\hline \multirow{2}{*}{ Blood pressure Status } & $\begin{array}{l}\text { Normotensive } \\
\quad(\mathrm{n}=84)\end{array}$ & $5(5.95 \%)$ & $25(29.76 \%)$ & $43(51.20 \%)$ & $11(13.10 \%)$ & \multirow{2}{*}{0.0003} \\
\hline & $\begin{array}{c}\text { Hypertensive } \\
(\mathrm{n}=69)\end{array}$ & $2(2.89 \%)$ & $3(4.35 \%)$ & $28(40.57 \%)$ & $36(52.17 \%)$ & \\
\hline
\end{tabular}

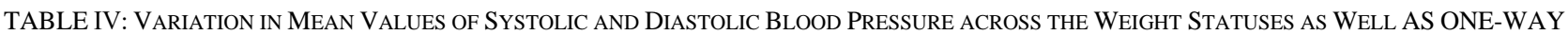
ANOVA ANALYSIS

\begin{tabular}{|c|c|c|c|c|c|c|}
\hline \multicolumn{7}{|c|}{ ANOVA ANALYSIS } \\
\hline \multirow{2}{*}{\multicolumn{2}{|c|}{ Parameter }} & \multicolumn{4}{|c|}{ Weight Status } & \multirow{2}{*}{$\begin{array}{c}\text { One Way } \\
\text { ANOVA } \\
\text { p-value }\end{array}$} \\
\hline & & Underweight & Normal Weight & Over Weight & Obese & \\
\hline Blood Pressure & $\begin{array}{c}\text { systolic } \\
\text { Mean }( \pm \mathrm{SD})\end{array}$ & $127.57( \pm 10.67)$ & $126.89( \pm 9.63)$ & $135.52( \pm 17.46)$ & $152.64( \pm 19.74)$ & 0.004 \\
\hline Status & $\begin{array}{c}\text { Diastolic } \\
\text { Mean }( \pm \text { SD })\end{array}$ & $81.71( \pm 7.29)$ & $83.21( \pm 4.68)$ & $89.39( \pm 7.57)$ & $95.40( \pm 9.75)$ & 0.0001 \\
\hline
\end{tabular}

\section{DISCUSSION}

Our study has highlighted the influence of obesity on hypertension along with prevalence of hypertension and obesity among regional and general population of Pak Arab Society, Lahore, Pakistan. In the start of data analysis, we noted the high prevalence of obesity and hypertension. Obesity prevalence was $30.70 \%$ while hypertension prevalence was $45.10 \%$. However, another Pakistani study has reported lower obesity prevalence $27.80 \%$, in comparison to our study [18.] Lower prevalence of hypertension as compared to our study results, has been reported by another Pakistani study that was conducted in Karachi [19]. An Indian study reported $32.90 \%$ prevalence of hypertension [11].

Then we observed that obesity prevalence was higher among women than men and gender was associated with weight status significant statistically $(\mathrm{p}=0.040)$ and it was 
assessed by chi-square test. However, difference in BMI mean values across the gender was insignificant $(p=0.779)$ with higher BMI among women and it was determined by independent sample t-test. A Pakistani study that was conducted in Multan, reported similar finding about obesity and gender association but conflicting about variation in prevalence of obesity across the gender with higher prevalence of obesity among men [18]. A global study also showed that higher obesity prevalence among women than men [20].

Similarly, we noticed the difference in hypertension prevalence, across the gender, and it was higher among men than women, however, it was not associated with gender significantly $(p=0.072)$ and it was assessed via Chi-square test. Then, we discovered that hypertension was linked with weight status significant statistically $(\mathrm{p}=0.0003)$ and it was determined by chi-square test. Moving forward during data analysis we found that disparity in BMI mean values over blood pressure status was significant statistically $(\mathrm{p}=0.0001)$ with higher mean BMI value among hypertensive people. It was checked by independent sample t-test. Then, in next step we detected that variation in mean values of systolic and diastolic blood pressures among four weight statuses was significant $(\mathrm{p}=0.004$ for systolic blood pressure variation and $\mathrm{p}=0.0001$ for diastolic blood pressure) and evaluated by OneWay-ANOVA analysis. Mean values of both systolic and diastolic bold pressure were highest among obese people while lowest among people with normal weight in case of systolic blood pressure whereas, lowest among underweight people in case of diastolic blood pressure. Higher blood pressure among obese persons have been noticed in different studies around the globe [15], [21].

At the end of data analysis, we detected BMI mean values among four statuses of weight and difference in BMI mean values among these four classes pf weight status was significant $(\mathrm{p}=0.0003)$, and it was assessed by One-WayANOVA test. It was also noted in a study that was conducted at Phalia, Pakistan [16].

In literature, Increased expression of natriuretic peptide clearance receptor in fatty tissues, Obstructive sleep apnea syndrome, and genetic predisposition have been considered as the causes of raised blood pressure among obese individuals [22]-[25]. Although some of these are causes are genetically determined and run-in families however, by reduction in weight via exercise and balanced diet, we not only avoid obesity but hypertension as well, and resultantly the diseases caused by hypertension.

Despite of limitations of our study because of crosssectional nature, our study still has brought very crucial issue in consideration. To the extent we know, this is only study that has conducted at Pak Arab Society, Lahore, Pakistan to assess the impact of obesity on hypertension. Our study suggests people should take actions to reduce weight and then as a reward they can avoid hypertension and complications of hypertension. Further, researches are needed to determine the real cause of hypertension among obese people at local and national level.

\section{CONCLUSION}

In a nutshell, this study indicates high prevalence of hypertension and obesity among recruited population of Pak Arab Society, Lahore, Pakistan and significant association of hypertension and obesity was present in our study population. Moreover, gender difference in obesity and hypertension was noted. Obesity incidence was higher among women while hypertension incidence was higher among men. So, by application of suitable interventions for weight reduction we would be able to control blood pressure as well along with its complications.

\section{ACKNOWLEDGMENT}

We (Jehanzeb Akram, the principal author, Tayyab Mumtaz Khan, the co-principal author and corresponding author, and all co-authors) thank all respected individuals, who participated in this research.

\section{REFERENCES}

[1] Kearney PM, Whelton M, Reynolds K, Whelton PK, He J. Worldwide prevalence of hypertension: a systematic review. Journal of hypertension. 2004 Jan 1;22(1):11-9.

[2] Murray CJ, Lopez AD. Mortality by cause for eight regions of the world: Global Burden of Disease Study. The lancet. 1997 May 3;349(9061):1269-76.

[3] Mendis S, Armstrong T, Bettcher D, Branca F, Lauer J, Mace C, Poznyak V, Riley L, Silva VD, Stevens G. Global status report on noncommunicable diseases 2014. World health organization. 2014 Feb:84.

[4] Tabrizi JS, Sadeghi-Bazargani H, Farahbakhsh M, Nikniaz L, Nikniaz Z. Prevalence and associated factors of prehypertension and hypertension in Iranian population: the Lifestyle Promotion Project (LPP). PloS one. 2016 Oct 26;11(10):e0165264.

[5] Saleem F, Hassali AA, Shafie AA. Hypertension in Pakistan: time to take some serious action. British Journal of General Practice. 2010 Jun $1 ; 60(575): 449-50$.

[6] Isselbacher KJ, Braunwald E, Petersdorf RG, Wilson JD, Martin JB, Fauci AS. Harrison's principles of internal medicine. McGraw-Hill; 1987.

[7] Strandgaard S. Hypertension and stroke. Journal of hypertension. Supplement: official journal of the International Society of Hypertension. 1996 Oct 1;14(3):S23-7.

[8] Escobar E. Hypertension and coronary heart disease. Journal of human hypertension. 2002 Mar;16(1):S61-3.

[9] Chobanian AV, Bakris GL, Black HR, Cushman WC, Green LA, Izzo Jr JL, Jones DW, Materson BJ, Oparil S, Wright Jr JT, Roccella EJ. Seventh report of the joint national committee on prevention, detection, evaluation, and treatment of high blood pressure. hypertension. 2003 Dec 1;42(6):1206-52.

[10] Prabakaran J, Vijayalakshmi N, VenkataRao E. Prevalence of hypertension among urban adult population (25-64 years) of Nellore, India. Int J Res Dev Health. 2013 Apr;1(2):42-9.

[11] Singh S, Shankar R, Singh GP. Prevalence and associated risk factors of hypertension: a cross-sectional study in urban Varanasi. International journal of hypertension. 2017 Oct;2017.

[12] El Bcheraoui C, Memish ZA, Tuffaha M, Daoud F, Robinson M, Jaber S, Mikhitarian S, Al Saeedi M, AlMazroa MA, Mokdad AH, A Rabeeah AA. Hypertension and its associated risk factors in the Kingdom of Saudi Arabia, 2013: a national survey. International journal of hypertension. 2014 Aug 6;2014.

[13] Wei Q, Sun J, Huang J, Zhou HY, Ding YM, Tao YC, He SM, Liu YL Niu JQ. Prevalence of hypertension and associated risk factors in Dehui City of Jilin Province in China. Journal of human hypertension. 2015 Jan;29(1):64-8.

[14] Redon J. Hypertension in obesity. Nutrition, metabolism, and cardiovascular diseases: NMCD. 2001 Oct 1;11(5):344-53.

[15] Diaz ME. Hypertension and obesity. Journal of human hypertension. 2002 Mar;16(1):S18-22.

[16] Bibi S, Khan TM, Zafar WM, Umer MJ, Iqbal UF, Maqsood MA, Khan S, Khalil S, Mumtaz M. Prevalence of Obesity and Impact of Menopause on It among Women of Rural Area of Punjab, Pakistan. 
[17] Kenchaiah S, Evans JC, Levy D, Wilson PW, Benjamin EJ, Larson MG, Kannel WB, Vasan RS. Obesity and the risk of heart failure. New England Journal of Medicine. 2002 Aug 1;347(5):305-13.

[18] Aslam M, Saeed A, Pasha GR, Altaf S. Gender differences of body mass index in adults of Pakistan: A case study of Multan city. Pakistan Journal of Nutrition. 2010;9(2):162-6.

[19] Safdar S, Omair A, Faisal U, Hasan H. Prevalence of hypertension in a low income settlement of Karachi, Pakistan. Prevalence. 2004 Oct.

[20] Garawi F, Devries K, Thorogood N, Uauy R. Global differences between women and men in the prevalence of obesity: is there an association with gender inequality? European journal of clinical nutrition. 2014 Oct;68(10):1101-6.

[21] Al-Nozha MM, Abdullah M, Arafah MR, Khalil MZ, Khan NB, AlMazrou YY, Al-Maatouq MA, Al-Marzouki K, Al-Khadra A, Nouh MS, Al-Harthi SS. Hypertension in saudi arabia. Saudi medical journal. 2007 Jan 1;28(1):77.

[22] Sarzani R, Dessì-Fulgheri P, Salvi F, Serenelli M, Spagnolo D, Cola G, Pupita M, Giantomassi L, Rappelli A. A novel promoter variant of the natriuretic peptide clearance receptor gene is associated with lower atrial natriuretic peptide and higher blood pressure in obese hypertensives. Journal of hypertension. 1999 Sep 1;17(9):1301-5.

[23] Rumantir MS, Vaz M, Jennings GL, Collier G, Kaye DM, Seals DR, Wiesner GH, Brunner-La Rocca HP, Esler MD. Neural mechanisms in human obesity-related hypertension. Journal of hypertension. 1999 Aug 1;17(8):1125-33.

[24] Grassi G. Obesity, sympathetic activity, sleep apnea. J Hypertens. 1999; 17:1059-60.

[25] Bao G, Metreveli N, Fletcher EC. Acute and chronic blood pressure response to recurrent acoustic arousal in rats. American journal of hypertension. 1999 May 1;12(5):504-10.

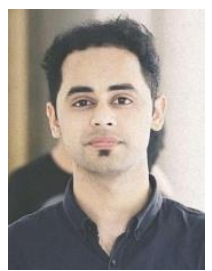

Dr. Tayyab Mumtaz Khan

Place of Birth: Lahore, Pakistan.

Date of Birth: $23^{\text {rd }}$ March 1996.

Educational Background: MBBS.

Rawalpindi Medical University Rawalpindi, Pakistan. 